\title{
Direct assessment of tensile stress-crack opening behavior of Strain Hardening Cementitious Composites (SHCC)
}

\author{
Eduardo B. Pereira ${ }^{\mathrm{a}, *}$, Gregor Fischer ${ }^{\mathrm{b}}$, Joaquim A. O. Barros ${ }^{\mathrm{a}}$ \\ ${ }^{a}$ ISISE - University of Minho, Department of Civil Engineering, School of Engineering, \\ Azurem, 4810-058 Guimaraes, Portugal. \\ ${ }^{b}$ Technical University of Denmark (DTU), Department of Civil Engineering, Brovej, \\ building 118, DK-2800 Kgs. Lyngby, Denmark.
}

\begin{abstract}
The process of designing Strain Hardening Cementitious Composites (SHCC) is driven by the need to achieve certain performance parameters in tension. These are typically the pseudo-strain hardening behavior and the ability to develop multiple cracks. The assessment of the tensile load-deformation of these materials is therefore of great importance and is frequently carried out by characterizing the material tensile stress-strain behavior. In this paper an alternative approach to evaluate the tensile performance of SHCC is investigated. The behavior of the material in tension is studied at the level of a single crack and the tensile performance is evaluated in terms of the tensile stress-crack opening behavior. The experimental procedure and test setup used are discussed. The derived tensile stress-crack opening behavior is utilized to analyze and compare the influence of various composite parameters on the resulting tensile behavior. The deformations occurring during tensile
\end{abstract}

\footnotetext{
${ }^{*}$ Corresponding Author:

Email address: eduardo.pereira@civil.uminho.pt (Eduardo B. Pereira)
} 
loading are furthermore examined using a digital image analysis technique to gain detailed insight into the crack formation, propagation and opening phases.

Keywords: E. Fiber Reinforcement, C. Tensile Properties, C. Finite

Element Analysis, B. Crack Detection, Material Design.

\section{Introduction}

The recent technological development of a wide variety of fibers has been 3 creating new opportunities for the development of fiber reinforced cementitious composites as structural materials. The behavior of these distinct fibers, 5 which are dispersed in the cementitious matrix, can assume diverse forms and

dimensions, allowing the development of numerous functional properties of these materials. In particular, when fiber reinforced cementitious composites are designed to develop strain hardening in tension, so-called Strain Hardening Cementitious Composites (SHCC) are obtained. From the viewpoint of structural design, the strain-hardening ability in tension is often referred to as the most relevant feature of SHCC.

Pseudo-strain hardening in tension exhibited by SHCC is the consequence of the development of multiple cracks under tensile loading. Tensile hardening at the level of a single crack is the main prerequisite of this composite response to tensile loading. This material property represents a dual advantage in engineering applications: while more cracks develop at the same tensile deformation level, the individual crack openings are significantly smaller. The result of this multiple cracking behavior is enhanced durability and better preservation of functional properties in the structural elements. Conversely, 
higher energy dissipation ability exists at the level of a single crack, which is amplified by the large number of cracks typically developed. These materials are therefore designed to exhibit high toughness and significant tolerance to damage in tension. Over the past few decades the research carried out in SHCC materials has suggested different approaches to the design of these materials $[1,2]$. Engineered Cementitious Composites (ECC), a class of cement based materials typically reinforced with Polyvinyl Alcohol (PVA) fibers, are an example of SHCC materials showing high tensile strain hardening ability (between $3 \%$ and $7 \%$ of ultimate tensile strain) at an ultimate tensile strength of $5 \mathrm{MPa}[3,4]$.

The mechanical behavior in tension of SHCC materials is the result of a delicate balance of multiple factors. The interfacial bonding and fiber pull-out properties, the material parameters of the fibers and of the matrix, the distribution of flaw sizes in the matrix, the fiber orientation and their dispersion in the matrix play an important role in the resulting composite mechanical behavior. The study of the influence of these parameters individually is complex, given that they perform in a highly coupled manner. The assessment of the tensile performance of SHCC materials is therefore of great importance, for an efficient material design as well as for the appropriate constitutive modeling in structural applications. SHCC materials research has been mostly dedicated to the characterization of their tensile stress-strain behavior, particularly dealing with their unique characteristic, the pseudostrain hardening ability in tension $[4,5]$. The type of test mostly used is the direct tension test using dog bone-shaped (dumbell-shaped) or coupon specimens [5-7]. The material tensile stress-strain behavior is thereby assessed 
as well as the potential of the material to develop multiple cracks. The direct tension tests are experimentally demanding, therefore inverse analysis is also alternatively used to derive indirectly the stress-strain or the stressseparation law from bending tests [8]. Other test setups used are inspired by common test methods adopted to extract the fracture parameters of concrete and other tension softening fiber reinforced cementitious composites. These test methods include the Compact Tension test (CTT), the Wedge Splitting test (WST), the Split Cylinder Tensile Strength Test and the Three Point Bending Test (see for example [9-13]). However, the initiation of multiple cracks and the individual particular testing conditions interfere with the explicit and objective characterization of SHCC constitutive properties.

In this study an alternative approach to the assessment of the tensile behavior of SHCC materials is investigated. This approach is based on the characterization of the tensile stress-crack opening behavior of SHCC at the level of a single crack. The main obstacle to this strategy is the difficulty associated with obtaining a single crack when the material is especially designed to develop multiple cracks. To produce adequate mechanical conditions for the initiation and evolution of a single crack, the stress fields generated in test specimens under tension may be locally intensified using geometrical constrictions or notches. This procedure is well known from the characterization of the tensile stress-crack opening behavior of tension softening fiber reinforced cementitious composites. Research has been carried out in this field, using different test methods to assess the post-cracking behavior of fiber reinforced cementitious composites in direct tension (see for example $[14,15])$. However, when pseudo-strain hardening materials are considered 
this strategy shows difficulties in keeping the crack single throughout the entire loading sequence [16]. Nevertheless, previous work has shown that if the geometry of the specimen is modified, a single crack may be obtained and mechanically characterized $[17,18]$. In this study the geometry of the specimen was investigated and special attention was dedicated to minimizing the thickness of the notches created in the specimens. The motivation supporting this procedure is the possibility to assess directly and objectively important features of the composite behavior in tension, also when the material shows pseudo-strain hardening in tension. The benefits extend beyond the material design process. The tensile stress-crack opening relationship is of major importance to the constitutive modeling of the material behavior, which is a central element in the numerical simulation of structures. Seeking optimal usage of SHCC material properties, research has been carried out to develop numerical modeling strategies especially suited to simulate the behavior of SHCC structures [19]. In particular, the single crack cohesive law was adopted by [20] to characterize the tensile behavior of SHCC in a numerical model. Typically, the performance and accuracy of these models depend on the objective assessment of the SHCC material behavior, which motivates the exploration of experimental procedures that consistently lead to an explicit tensile stress-crack opening characterization of fiber reinforced cementitious composites using notched specimens [15, 21].

The verification that a single crack is indeed obtained during the entire testing sequence is important for the unique characterization of the tensile stress-crack opening behavior of SHCC. To help with the identification of the various crack initiation and propagation stages, an image-based monitoring 
system has been used to document the generated deformations at the surface of the specimens during testing. The so-called Digital Image Correlation (DIC) technique involves the comparison of two digital images of the surface of an object before and after deformation using an appropriate correlation technique [22]. The accuracy of the correlation between the recorded images depends mainly on the quality of the image speckle pattern (including light conditions) and the resolution of the imaging system [23]. By using DIC, the crack initiation and propagation stages in direct tension in notched SHCC specimens have been monitored and characterized. This is particularly important during the early stages of the testing sequence, when the crack is developing and while the tensile stresses gradually transfer from the matrix to the fibers bridging the crack.

\section{Materials and Methods}

\subsection{Materials}

In this study the tensile behavior of seven different fiber reinforced cementitious composites was assessed. The materials used in the composition of the cementitious matrix were essentially the same for all composites, and the type and volume fraction of fiber reinforcement was varied. The matrix composition in terms of the weight of each ingredient for a total volume of 1 $\mathrm{dm}^{3}$ is presented in Table 1.

Fibers of three different natures were used: PVA (polyvinyl alcohol), PAN (polyacrylnitrile) and PP (polypropylene). The main geometrical and mechanical properties of these fibers are presented in Table 2 
Table 1: Weight of the materials used for $1 \mathrm{dm}^{3}$ of cementitious matrix.

\begin{tabular}{llll} 
Cement & Fly ash & Fine sand $(0.17 \mathrm{~mm})$ & Quartz powder \\
\hline $428 \mathrm{~g}$ & $856 \mathrm{~g}$ & $150 \mathrm{~g}$ & $150 \mathrm{~g}$ \\
\hline
\end{tabular}

Table 2: Main properties of the fibers used.

\begin{tabular}{lrrr}
\hline Fiber & $\begin{array}{r}\text { Tensile strength } \\
(\mathrm{MPa})\end{array}$ & $\begin{array}{r}\text { Length } \\
(\mathrm{mm})\end{array}$ & $\begin{array}{r}\text { Diameter } \\
(\mu \mathrm{m})\end{array}$ \\
\hline PVA & 1600 & 8 & 40.0 \\
PP & 900 & 12 & 40.0 \\
PAN 1.5 & 826 & 6 & 12.7 \\
PAN 3.0 & 767 & 6 & 18.0 \\
PAN 6.7 & 413 & 6 & 26.8 \\
PAN 30 & 295 & 6 & 57.0 \\
\hline
\end{tabular}

120

123 
SHCC materials are designed to develop multiple cracks in tension, consequently the formation of a single crack is naturally prevented by the material. To meet this requirement, different geometries of notched specimens were previously investigated, and their ability to promote the initiation and propagation of a single crack was verified. Special attention was dedicated to the minimization of the thickness of the created notches.

In general terms, cracking saturation in SHCC materials is achieved when, while new cracks form, the decreasing crack spacing reaches a critical value that is equal the load transfer length required to induce new cracking. This load transfer length, determined by the fiber properties, the matrix fracture parameters and the fiber-matrix interaction properties, is a lower bound limit to the crack spacing in the composite. The notch thickness adopted in this investigation, $0.5 \mathrm{~mm}$, is well below the typical crack spacings found in the literature and observed in un-notched SHCC specimens tested in direct tension (see for example [24]). These crack spacings can reach values as low as $5 \mathrm{~mm}$, but seldom below $2 \mathrm{~mm}$. The notch thickness and specimen geometry selected in this study are aimed at preventing the possibility of additional cracking to occur in the immediate vicinity of the primary induced crack.

The specimen dimensions and final geometry are presented in Figure 1. The length of the specimen was $120 \mathrm{~mm}$ and the free distance between the fixed ends during testing was $70 \mathrm{~mm}$. To produce six specimens of each composite, plates of $600 \times 125 \times 20 \mathrm{~mm}^{3}$ (length $\times$ width $\times$ thickness) were cast, sealed and left to cure for 28 days. The casting surface of the plates was then ground to a thickness of $12 \mathrm{~mm}$ and a matrix of $2 \times 3$ specimens was cut from the central part of the plate (see Figure 1. After curing, the $0.5 \mathrm{~mm}$ thick 
notches were cut in the coupon specimens using a small diamond cutting disc. The high rotation speed of the disc and a delicate setup were used to avoid causing damage in the specimens.

The testing sequence consisted of applying a displacement controlled constant axial displacement rate of $5 \mu \mathrm{m} / \mathrm{s}$, transmitted by the hydraulic actuator to the specimen by means of two hydraulic grips providing fixed support to both ends of the specimen (rotations and transverse displacements were restrained). During testing, the opening of the notch was evaluated by means of two clip gages positioned in opposite sides as shown in Figure 2.

The example of one specimen adopting the final geometry proposed in

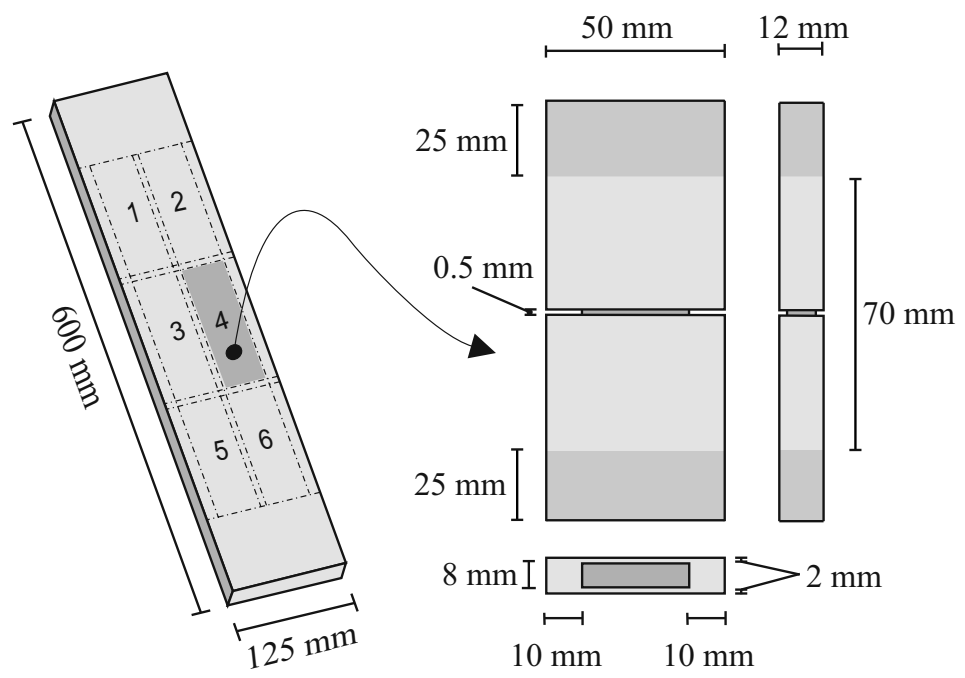

Figure 1: Specimen geometry used in the assessment of the tensile stress-crack opening behavior.

162

this study is presented in Figure 3 where a single crack was formed and characterized in tension. After adopting this geometry the formation of a single crack was consistently obtained in tests conducted subsequently. 


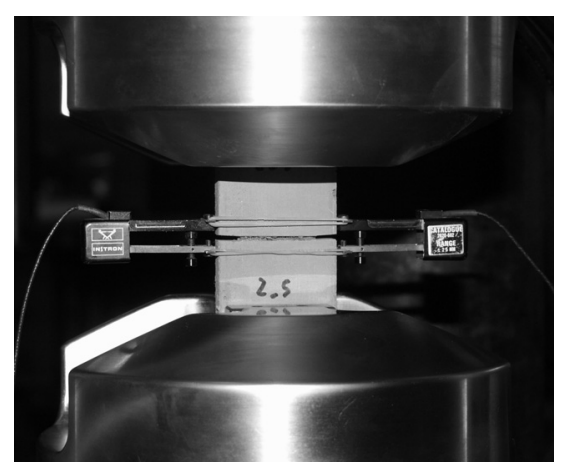

Figure 2: Tensile test setup including supports and clip gages.

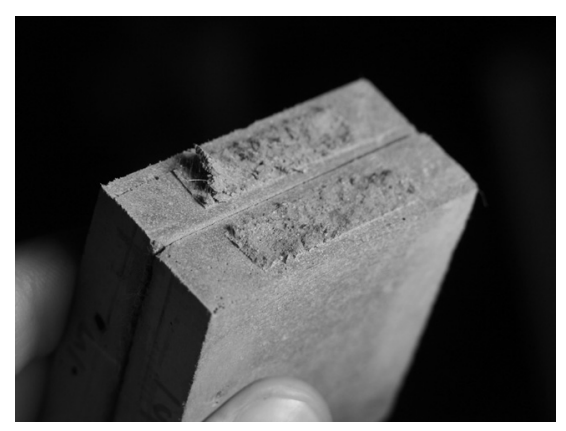

Figure 3: Single crack obtained after testing.

\subsection{Tensile stress-crack opening results}

The results obtained after testing the specimens in direct tension are presented in Figure 4. The tensile stress values (nominal tensile stress) presented were obtained by computing the ratio between the experimental tensile load and the net area of the notched cross-section $\left(8 \times 30 \mathrm{~mm}^{2}\right)$. The crack mouth opening displacements (CMOD) were obtained by averaging the displacements measured in the two opposite clip gages, although these 

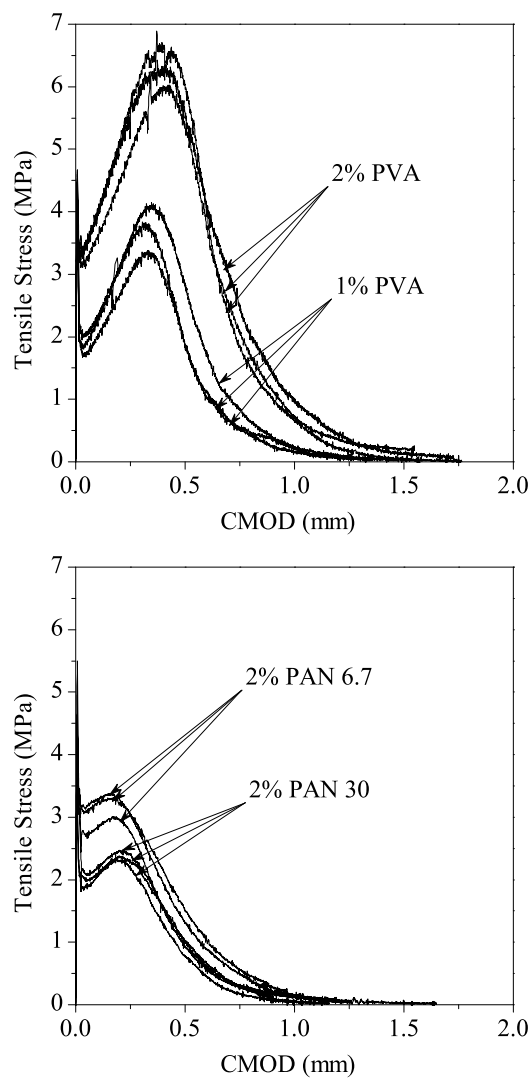
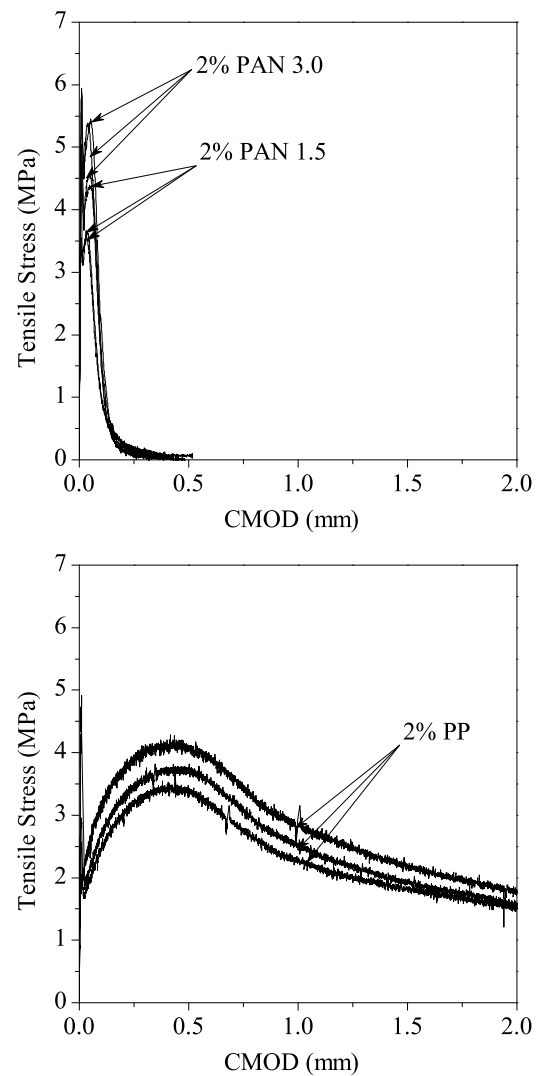

Figure 4: Tensile stress-CMOD of the tested composites.

were later verified to be practically similar. The adoption of the fixed supports contributed to this requirement of minimizing the difference between the displacements observed in the opposite clip gages. The distance between the two sampling points of each clip gage was $25 \mathrm{~mm}$.

For each composite, the results of three of the six specimens tested are shown. The upper and lower limit results are presented to show an envelope of the obtained behavior. 


\section{Crack initiation}

\subsection{Numerical model}

The notches inserted at the middle section of the specimens produce a local intensification of the stress field. This intensification is desirable, regarding the intention of inducing the formation of a single crack during tensile loading. The initiation of the crack at the corners of the notched cross-section and its subsequent propagation occur rapidly, while the opening of the crack tip is still small. At this stage, the fracture micro-mechanisms depend almost exclusively on the properties of the matrix. In order to estimate the effect of the local intensification of the stress field induced by the notch on the generation of the crack plane, a 3D finite element model was constructed. Considering the very small deformations at which the formation of the crack occurs, the numerical model represents a valuable contribution to understand the dominant micro-mechanisms occurring at this stage of the cracking process. Assuming that the specimen is composed of the cementitious matrix only, the contribution of the adopted geometry and of the notches to the initiation and propagation of a single crack plane was studied. The geometry of the left half of the modeled portion of the specimen and the adopted finite element mesh are shown in Figure 5 and Figure 6, respectively.

In Figure 7 the mesh near the lateral notch tip and at the mid-plane of the specimen $\left(\mathrm{x}_{3}=0\right)$ is shown. In Figure 8 the mesh near the lateral notch tip is shown, when looking from the top $\left(\mathrm{x}_{3}=6 \mathrm{~mm}\right)$.

One quarter of the specimen was modeled. In Figure 5 and Figure 6 only 


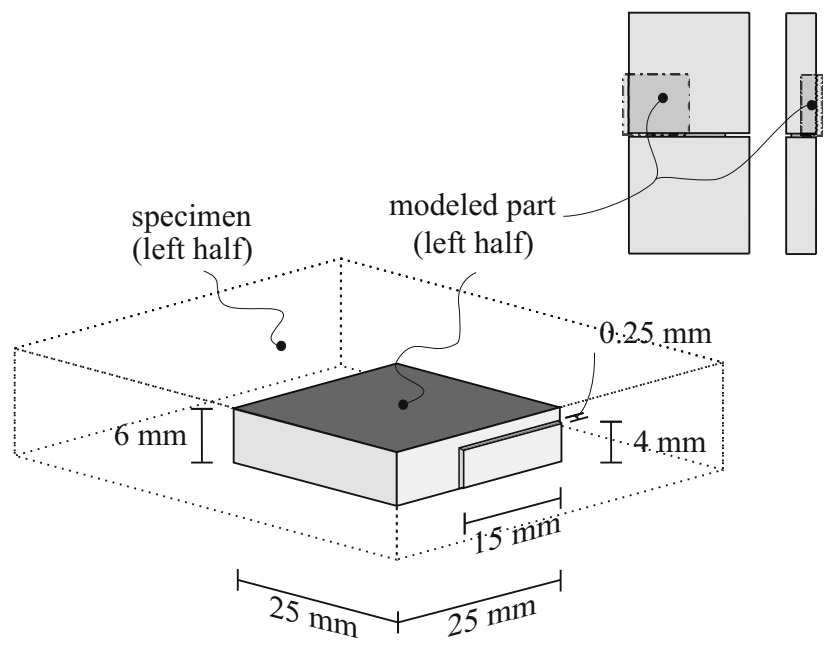

Figure 5: Geometry of the left half of the modeled portion of the specimen.

the left half of the modeled portion is displayed. In Figure 7 and Figure 8 both left and right parts of the modeled portion are displayed, in a close view of the notch tip region. This simplification was possible due to the symmetry of the loading and the boundary conditions. Loading and structural bisymmetry with respect to the longitudinal axis $\left(\mathrm{x}_{2}\right.$, Figure 6$)$ of the specimen have been assumed. The boundary conditions adopted in the simulation are presented in Figure 6, where $\delta_{u}$ represents the prescribed displacement increment at each step of the numerical simulation.

The model was constructed using elastic 4-noded linear tetrahedral volume elements. The high geometrical gradients close to the notches were overcome with a significant increase of the number of elements in these regions, as represented in Figure 6, Figure 7 and Figure 8. The blunted shape of the notch tip, with a radius of $250 \mu \mathrm{m}$, was discretized with sufficient smoothness, relevant for the satisfactory approximation of the real stress intensity at the tip of the notches. The young modulus assigned to the elements was 


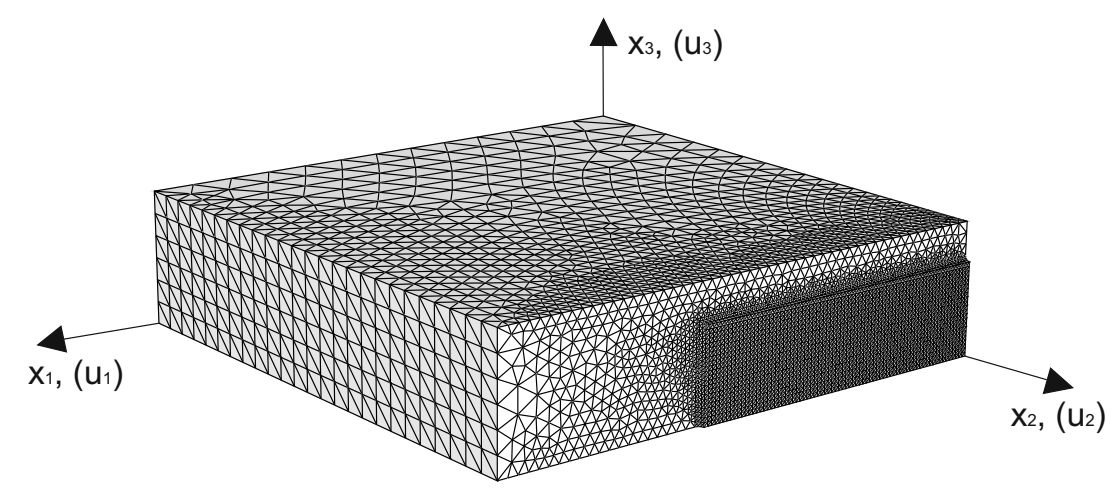

Boundary conditions:

$\mathrm{u}_{1}\left(\mathrm{x}_{1}=0\right)=0 ; \mathrm{u}_{2}\left(\mathrm{x}_{2}=0\right)=-\delta \mathrm{u} ; \mathrm{u}_{3}\left(\mathrm{x}_{3}=0\right)=0$

Figure 6: 3D finite element mesh used to model the specimen, boundary conditions and prescribed displacement increment.

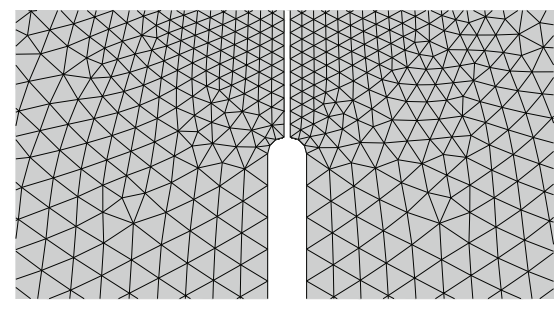

Figure 7: Mesh in the region of the notch tip, plane $\mathrm{x}_{3}=0$.

$20 \mathrm{GPa}$ and the Poisson coefficient was 0.2. One layer of interface elements was added in the notched section between the left and the right parts of the modeled quarter $\left(\mathrm{x}_{2}=25 \mathrm{~mm}\right.$ in Figure 6; Figure 9$)$. These interface elements were assigned with a linear softening stress-separation law, typical of cement-based materials exhibiting quasi-brittle behavior in tension (Figure 9). The local tensile strength, $\sigma_{c r}$, was assumed equal to $5.0 \mathrm{MPa}$, and the ultimate crack opening, $w_{u}$, equal to $10.0 \mu \mathrm{m}$ (Figure 9), which correspond to the matrix fracture energy, $G_{f}$, of $25 \mathrm{~J} / \mathrm{m}^{2}$. The local tensile strength, 


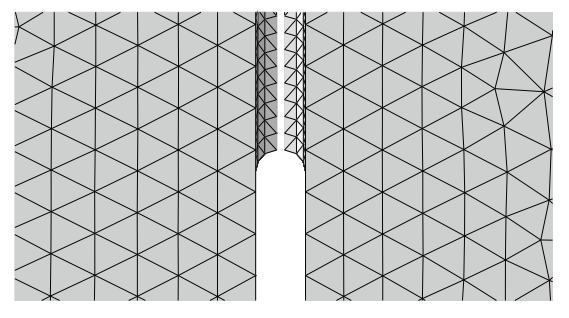

Figure 8: Mesh in the region of the notch tip, plane $\mathrm{x}_{3}=6 \mathrm{~mm}$.

$\sigma_{c r}$, was approximately estimated based on the average compressive strength results obtained for the composite reinforced with $2 \%$ of PVA fibers [LARUS PUBLICATION] and on the compressive strength-tensile strength relationships proposed by [25]. The ultimate crack opening, $w_{u}$ and the fracture energy, $G_{f}$, were aproximatelly estimated considering the experimental results obtained by other researchers dealing with the fracture properties of mortar and concrete [14, 26-29]. These parameters were not obtained by previous trial and error, or fitting to any specific group of the experimental results obtained. The estimated fracture parameters were directly used to analyze and explain the overall behavior and early conditions of crack initiation and propagation in the notched specimens.

\subsection{Numerical results}

In Figure 10 the general load-displacement curve obtained with the numerical model is presented. Increments 2, 10 and 36 of the increment-iterative algorithm are highlighted for three distinct load levels.

The effect of the notches and specimen geometry are best understood by visualizing the major principal stress fields produced at the longitudinal mid-plane of the specimen $\left(\mathrm{x}_{3}=0\right.$, Figure 6$)$. In Figure 11 these stress fields 


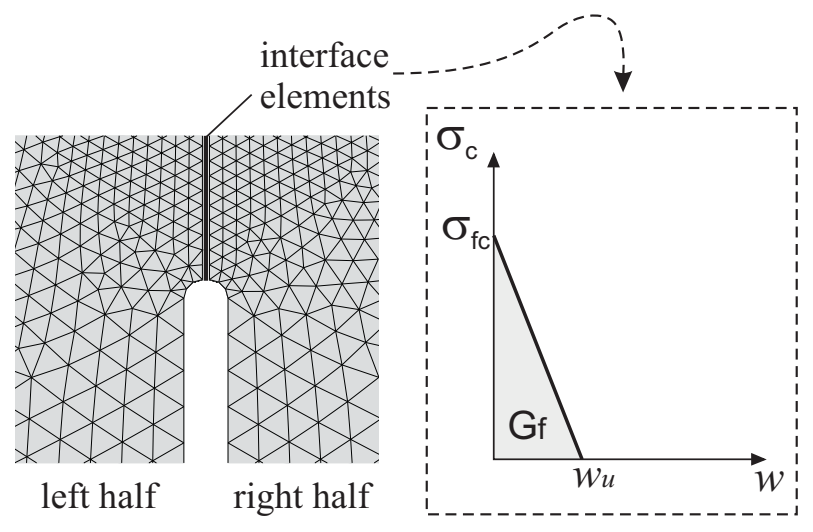

Figure 9: Detail of the 3D mesh close to the notch tip (plane $\mathrm{x}_{3}=0$ ) and stress-crack opening law adopted for the interface elements.

are represented for the two of the distinct load levels previously identified in Figure 10.

The stress fields generated at the outer surface of the specimen $\left(\mathrm{x}_{3}=6\right.$ mm, Figure 6) are also displayed in Figure 12. These allow the visualization of the effect produced by the longitudinal notches, which seem to help with keeping the path of the crack progression confined inside the notched section.

The numerical results presented in Figure 10 to Figure 12 show that the initiation and complete formation of the crack is greatly conditioned by the geometry of the specimen and the notched section. In Figure 10 the loaddisplacement curve shows a deviation from the linear elastic behavior starting almost from the onset of the tensile test. The presence of the slender notches creates high stress intensity at the corners of the rectangular notched crosssection, as shown in Figure 11 and Figure 12 for two distinct load levels. The major principal stress reaches the local tensile strength, $\sigma_{c r},(5.0 \mathrm{MPa})$ at the 


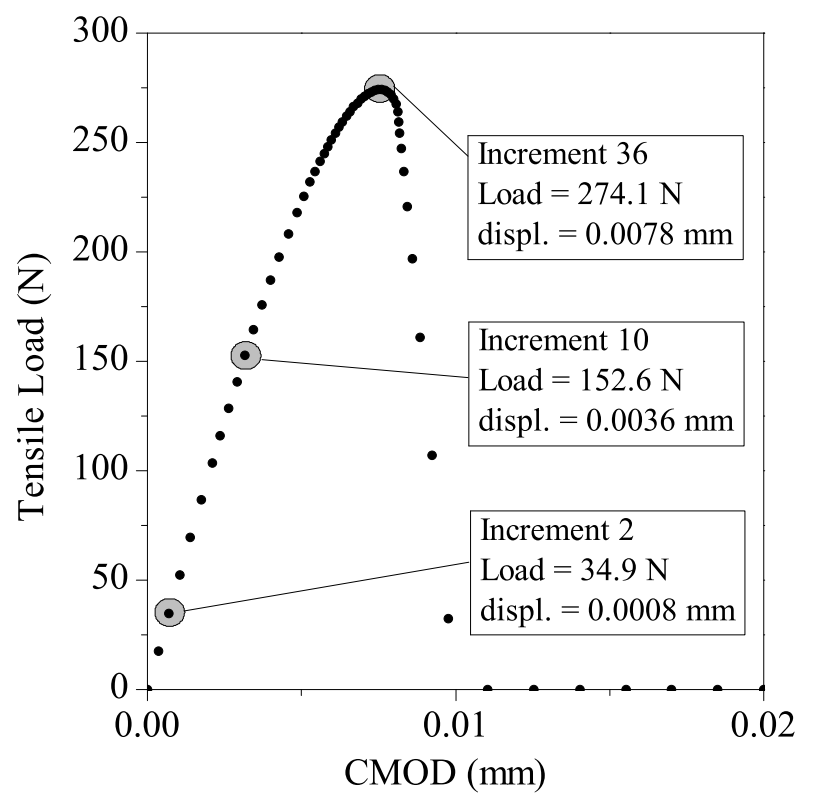

Figure 10: Axial load-displacement curve obtained with the numerical model of one quarter of the specimen.

referred corners when the tensile load reaches $13 \%$ of the tensile peak load (load increment 2, see Figure 10). Therefore cracking process starts early.

The results obtained allow establishing a relation between the local tensile strength, $\sigma_{c r}$, and the numerical peak nominal stress. Observing the results obtained with the numerical model, the peak load reaches the maximum value of $274.1 \mathrm{~N}$ (one quarter of the specimen). Dividing the peak load by the net area of the notched cross-section, the numerical peak nominal stress of $4.57 \mathrm{MPa}$ is obtained. The ratio between the numerical peak nominal stress and the local tensile strength, $\sigma_{c r}$, is $91 \%$, as a result of the local stress intensification produced by the notches and the geometry of the specimen. Disregarding the contribution of the fibers, this means that the local 


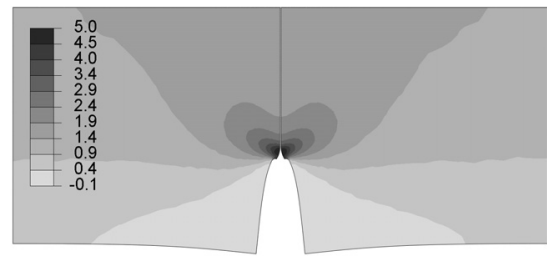

Load increment $=10$

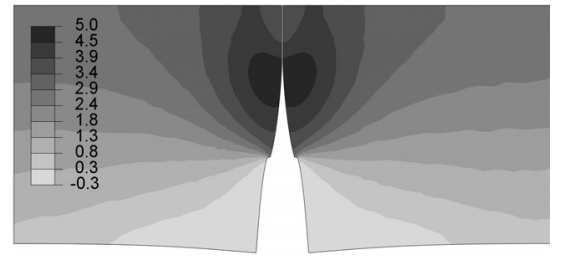

Load increment $=36$

Figure 11: Major principal stress field $(\mathrm{MPa})$ at the longitudinal mid-plane $\left(\mathrm{x}_{3}=0\right)$.

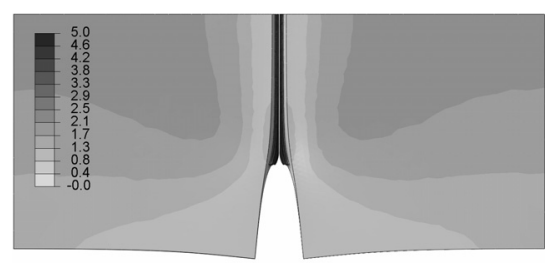

Load increment $=10$

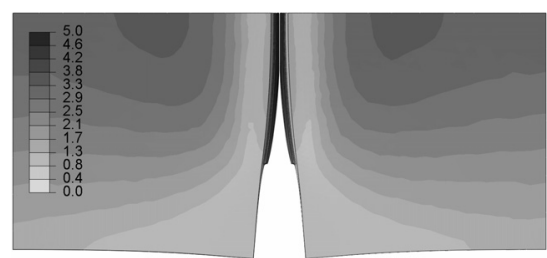

Load increment $=36$

Figure 12: Major principal stress field $(\mathrm{MPa})$ at the outer surface of the specimen $\left(\mathrm{x}_{3}=6\right.$ $\mathrm{mm})$. 
composite tensile cracking stress should be approximately $9 \%$ higher than the nominal peak cracking stress obtained experimentally using SCTT. This information can be used later on to estimate the tensile cracking stress for design purposes, based on the experimental results obtained with the SCTT.

When the local tensile strength, $\sigma_{c r}$, is reached at the corners of the notched section, the numerical nominal stress is $0.58 \mathrm{MPa}$. The necessary single crack plane is initiated at the corners, propagating afterwards rapidly to the middle of the notched section. The major principal stress fields in Figure 12 reveal that the stress intensification produced inside the notches is significant, while the stress levels outside the notches remain low. This effect produces the shielding of the crack plane, keeping the crack progression confined to the plane of the notched section. For the better understanding of the resulting 3D shielding effect of crack propagation, the major principal stress fields are displayed at three different load levels in Figure 13. As shown, the crack front is shaped and guided by the lateral long notches. The geometry of the specimen effectively contributes to the initiation and propagation of a single crack plane.

After the full development of the crack surface, the migration of the tensile stresses from the matrix to the fibers produces the rapid decrease of the tensile stiffness. Together with the simultaneous increase of the crack opening displacement, these contribute to keep the crack plane single. Nevertheless, if the bridging stresses reach very high levels in a later stage, secondary parallel crack planes may subsequently form. This event would affect the experimental tensile stress-crack opening curves obtained. The formation of secondary parallel cracks would result in visible abrupt load drops during the 


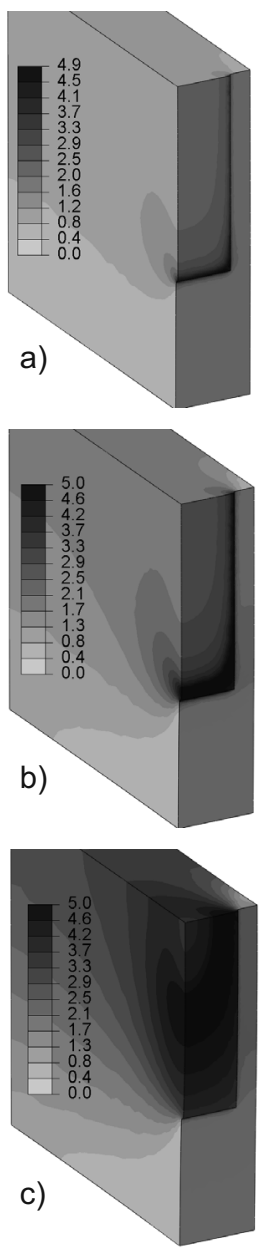

Figure 13: Major principal stresses (MPa) at the notched section for: a) load increment 2 , b) load increment 10 and c) load increment 36. 
post-cracking tensile hardening stage. In this case, the attainment of a single crack could be recovered by increasing the ratio between the net area of the un-notched and the notched cross-sections. The notch slenderness could be increased as well for the enhancement of the stress intensification at the tip of the notches, but in this case a different cutting technique would be necessary.

Observing again the major principal stresses in Figure 11, these show that an envelope of high stresses surrounding the crack tip exists. This envelope of high stresses follows the crack tip while it propagates from its onset at the corners of the notched section to the middle. The maximum size of the $90 \%$ stress envelope (the curve limiting the area where the stresses are equal or greater than $90 \%$ of the local tensile strength, $\sigma_{c r}$ ) is approximately $2.5 \mathrm{~mm}$ at the peak load (load increment 36, see Figure 10). The high stress in this region may cause initial damage in the matrix. In a later stage, with the increase of the crack bridging stress, these previously damaged areas may induce the formation of secondary cracks. In the present case, regarding the length and diameter of the fibers used, the size of this high stress envelope seems small enough to be considered insignificant, remaining the crack plane single. Nevertheless this should be reconsidered, if different material scales are involved, including the size of the fibers or the aggregates.

Before the full development of the crack surface, the resulting tensile behavior is mainly determined by the fracture properties of the matrix. The experimental and the numerical results at this stage are compared in Figure 14, Figure 15 and Figure 16. Considering the numerical results, the nominal stress was computed by multiplying the numerical load (see Figure 10) by 4 (due to the symmetry conditions) and dividing it by the net area of 


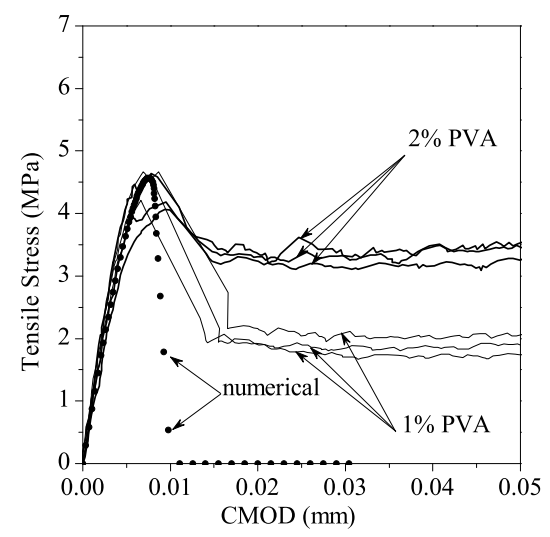

Figure 14: Numerical and experimental tensile stress-crack opening results for 1\% PVA and $2 \%$ PVA fiber reinforced composites.

the notched cross-section. The nominal stress values were plotted for each CMOD, that is the relative displacement in $x_{2}$ direction between two points placed in opposite sides of the notch. In the numerical model, these two points were placed in the same positions as the ones adopted by the clip gages in the experimental test-setup (see Figure 2).

In general, Figures 14, 15 and 16 show a good correlation between the experimental and the numerical results during the initial stage of cracking. The higher scatter of results obtained with PAN1.5 and PAN3.0 may be explained by the reduced diameter of these fibers. While in the fresh state, the thinner PAN1.5 and PAN3.0 fibers showed to be more difficult to mixture and disperse, due to their considerably greater specific surface. Since the matrix used was the same for all fibers and not adapted to perform better with the thinner ones, the adverse fresh mixture properties obtained with the PAN1.5 and PAN3.0 have resulted in decreased homogeneity after hardening. Nev- 


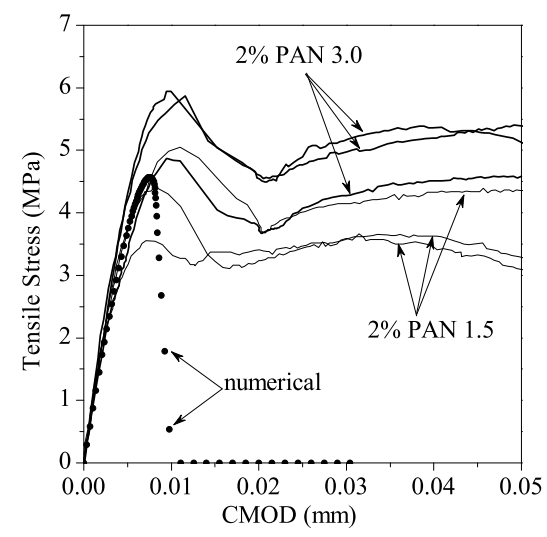

Figure 15: Numerical and experimental tensile stress-crack opening results for PAN 1.5 and PAN 3.0 fiber reinforced composites.

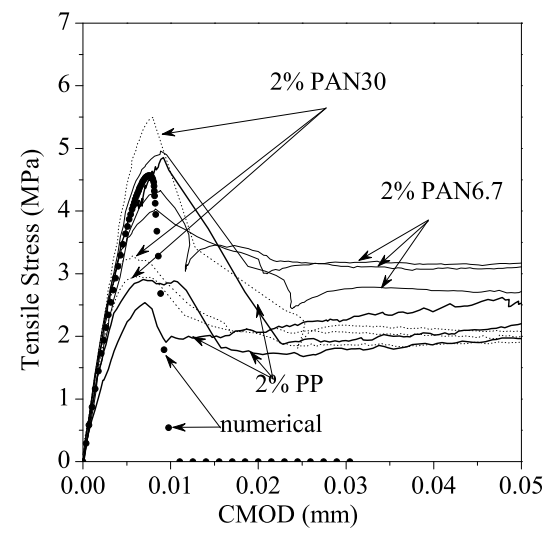

Figure 16: Numerical and experimental tensile stress-crack opening results for PAN 6.7, PAN 30 and PP fiber reinforced composites. 
ertheless, a substantial difference between the pre-peak behaviors obtained with the different fibers is observed. This suggests that the thinner fibers, due to their greater specific surface and the resulting enhanced bond with the matrix, contribute to the increase of the peak load at this stage. Their earlier mobilization in tension may explain this result. PAN3.0 fibers start contributing to resisting the tensile stresses at much smaller crack openings, delivering a superior contribution to the tensile hardening mechanisms in the early stage of the crack formation and propagation. This effect was not so visible for the PAN1.5 fibers, due to the adverse fresh mixture properties and the resulting loss of homogeneity caused by the very small diameter of the fibers. In the case of the composites reinforced with PAN 30 and PP fibers (Figure 16), the higher scatter of results may be the consequence of a weaker fiber-matrix interfacial bonding. The weak activation of these fibers at this stage results in a less controlled process of the crack initiation and propagation, as shown by the frequent snap-back effects in the tensile stress-CMOD curves.

In the region of the tensile stress-crack opening behavior where cracking occurs, for most of the composites the post-cracking tensile softening occurs smoothly, with a gradual decrease of the tensile stress at increasing CMOD. For the PAN fiber reinforced composites, although the specimens reach higher stresses during cracking, the post-peak load decay is still smooth, due to the improved mobilization of the thinner fibers at this stage. This indicates that the fibers contribute to restrain the abrupt release of energy during the brittle failure of the matrix. It has been previously shown that the crack initiates and propagates in the matrix at a very limited period. During this 
period, depending on the geometry of the fibers and their interaction with the matrix, their activation in tension occurs earlier or later and more or less effectively. For the 1\% PVA fiber reinforced composite a small post-cracking jump of the CMOD seems to occur. The reduced reinforcement ratio in this case may be insufficient to restrain crack propagation in a controlled manner for a limited period. The abrupt energy release associated with the matrix fracture seems to be larger than the energy dissipation ability provided by only $1 \%$ of PVA fiber reinforcement.

The displacements observed when the cracking peak load is reached are very small. This stage of the single crack behavior seems to contain very relevant information for the characterization and design of the composite mechanics. The convenient characterization of the stage where the transfer of the tensile stresses from the matrix to the fibers occurs is essential for the successful design of the composite towards pseudo-strain hardening in tension and multiple cracking ability.

\section{Image analysis of crack propagation}

\subsection{Procedure and method}

The formation and propagation of the tensile crack was monitored at the surface of the specimens using a digital image-based system. The setup comprised two high resolution cameras, positioned $270 \mathrm{~mm}$ away from the specimen and $130 \mathrm{~mm}$ apart from each other (see Figure 17). Two lenses with focal length of $50 \mathrm{~mm}$ were used, allowing the observation of a $50 \mathrm{~mm}$ by $50 \mathrm{~mm}$ area in the surface of the specimen at a working distance of 270 $\mathrm{mm}$. Photos with a resolution of 4 megapixel were captured during testing 
with time intervals of 0.20 seconds. These photos were subsequently used for the continuous interpolation of the displacements and the derivation of the strain fields occurring at the surface of the inspected specimen.

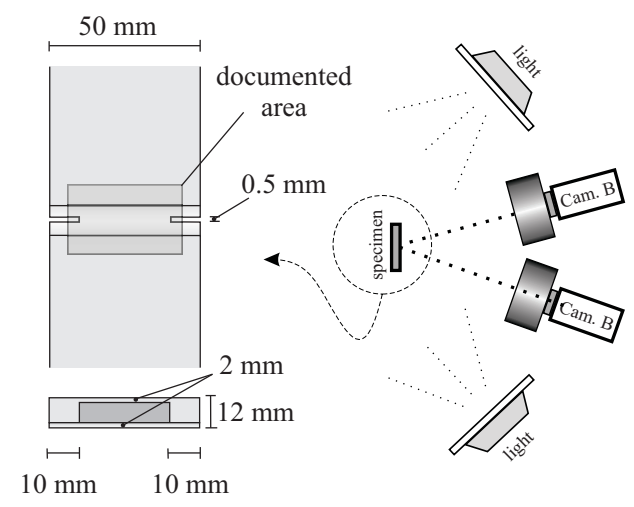

Figure 17: Geometry of the specimen and setup of the imaging system for the monitoring of surface deformations.

In order to allow the optical inspection of the crack, the geometry of the specimen near the notched section was altered. The original geometry (see Figure 1) was not viable because the intersection of the crack plane with the surface of the specimen was not visually accessible. The rounded shape and cylindrical surface at the notched area were adopted to approximate better the stress conditions of the original specimen in the notched section, as well as to allow the visual access to the intersection of the crack with the surface of the specimen (see Figure 17). Although the geometry of the specimen in the region of the notched cross section is different, the attainment of a single crack was verified visually. The crack surface obtained with one of the composites reinforced with 2\% of PVA fibers is shown in Figure 18. 


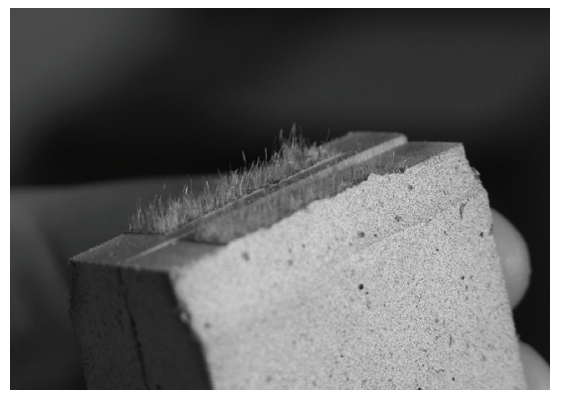

Figure 18: Single crack obtained with specimen used for the image analysis of cracking.

The optimal conditions of image correlation were met with the application of a speckle pattern at the surface of the specimen. Sufficient randomness and high contrast of the pattern captured from the surface is important for the continuous recognition and tracing of the shape and position of each facet. In the present case, each facet was composed of $10 \times 10$ pixels. Each pixel covered a real area of $25 \times 25 \mu \mathrm{m}^{2}$. The total area of $50 \times 50 \mathrm{~mm}^{2}$ was covered by a facet mesh overlay of $200 \times 200$ facets.

\subsection{Image analysis results}

Specimens with the geometry presented in Figure 17 were tested and a single crack was obtained and confirmed visually. The typical tensile stressCMOD behavior obtained is presented in Figure 19. A few relevant stages of the image-based monitoring procedure are identified, consisting of representative generic stages of the material single crack tensile behavior.

The strain fields were derived from the displacements computed at each facet adopting the digital correlation procedure. Each facet is treated as 


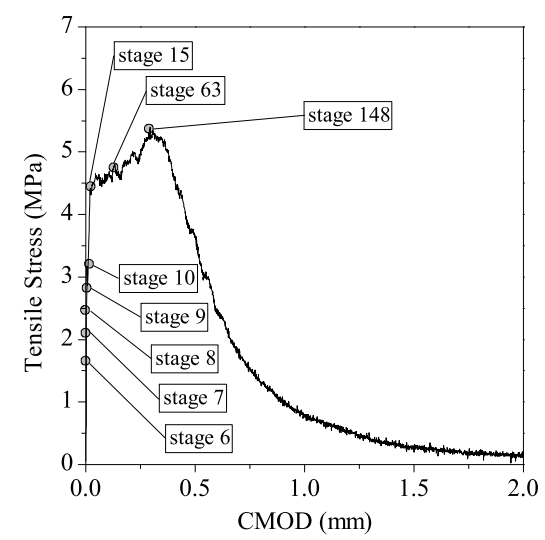

Figure 19: Tensile Stress-CMOD obtained during imaging and identification of relevant image-based monitoring stages.

a continuum and strains are derived from displacements according to the principles of continuum mechanics [22]. Cracks are, however, accurately represented by visualizing the major principal strains as if a continuum displacement field was occurring. The small facet size contributes to the high resolution with which the appearing cracks are identified and represented. The results in terms of major principal strains at the facet overlay are represented in Figure 20. The stages highlighted previously (see Figure 19) are identified in each frame.

The image-based monitoring of the cracking process near the notched area allowed the detailed tracing of the crack initiation and propagation stages. The initiation of the tensile crack is already visible in stage 9 , near the two opposite corners of the notched cross-section. $200 \mathrm{~ms}$ later the crack had propagated to the center of the notched section, as shown in stage 10 (see Figure 20). A straight and localized crack plane has formed. From stage 15 

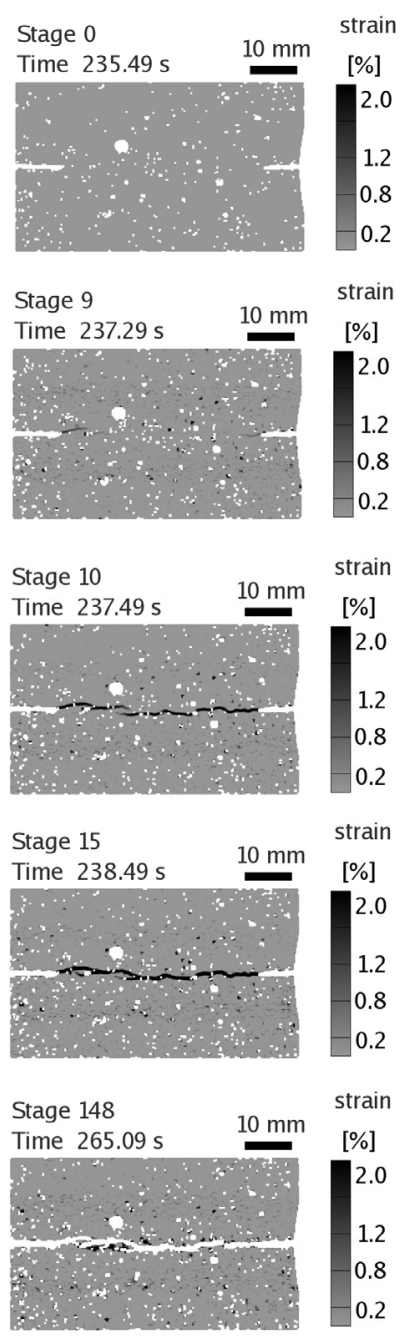

Figure 20: Major principal strains in the facets overlay based on the sequence of images of the specimen. The time step between stages is $200 \mathrm{~ms}$. 
onwards, the crack seems to remain single and fully developed. The fiber bridging mechanisms assure the necessary stress transfer ability for the specimen to keep withstanding an increasing tensile load.

To further analyze these results, the captured stages are presented in a closer view in Figure 21. For each stage, on the left hand side the original photo taken from the surface of the specimen is zoomed. On the right hand side the interpolated major principal strains are shown, together with a virtual clip gage showing the interpolated crack opening at the tip of the notch. The main advantage of this image-based monitoring technique is that it allows the simple and straightforward tracing of the evolution of the principal strains throughout the sequence of stages represented. The cracking processes are accurately revealed, from their onset.

The concept of an open discrete crack is rather unclear. The borderline between a preliminary diffuse micro-cracking region ahead of the crack tip and the subsequent coalesced crack is difficult to define. Nevertheless, the cracking topology was captured and identified with good resolution, much before it became visible. The observed thin and elongated shape of a hypothetical fracture processing zone ahead of the crack tip, typical of cementitious matrices, agrees with the observations of other researchers [30, 31].

As shown in Figure 21, the notch creates the necessary local stress or deformation conditions to the initiation of a single crack. After initiation, the crack propagates to the center of the specimen, remaining single and straight. After the full development of the crack throughout the entire specimen, the two opposite crack faces remain interconnected only by the fibers bridging them, which seems to occur at stage 15 . The mechanical characteristics of 
the subsequent hardening and softening stages are determined by the fiber reinforcement parameters only, including the number, geometry, mechanical properties, orientation and interfacial bonding established between the fibers and the surrounding matrix.

\subsection{Simulation of the post-cracking behavior}

Considering that a single crack was consistently obtained while performing the SCTT, the numerical model previously presented can adequately simulate the entire tensile response of the specimen if one layer of interface elements is positioned at the expected crack plane in the numerical model. For comparison, the traction-separation law assigned to the interface elements was derived from the SCTT tensile stress-crack opening response experimentally obtained for the $2.0 \%$ PVA fiber reinforced cementitious composite. The traction-separation law was derived by simply extracting the postcracking portion of the average experimental tensile stress-CMOD curve. All experimental measurements (10 per second) were used to define the tractionseparation law. The numerical results obtained are presented in Figure 22 and compared to the experimental average curve previously shown.

The numerical response obtained is mostly identical to the experimental, with slight differences observed at the initial stage. While the crack is forming, the specimen geometry influences somewhat the results obtained. As shown in Figure 11, although the tensile stresses in the region where the clip gages are positioned remain low, the crack tip opening displacement is slightly overestimated when evaluated outside the notch. This effect tends to be less significant after the crack is fully formed. Therefore, when the 

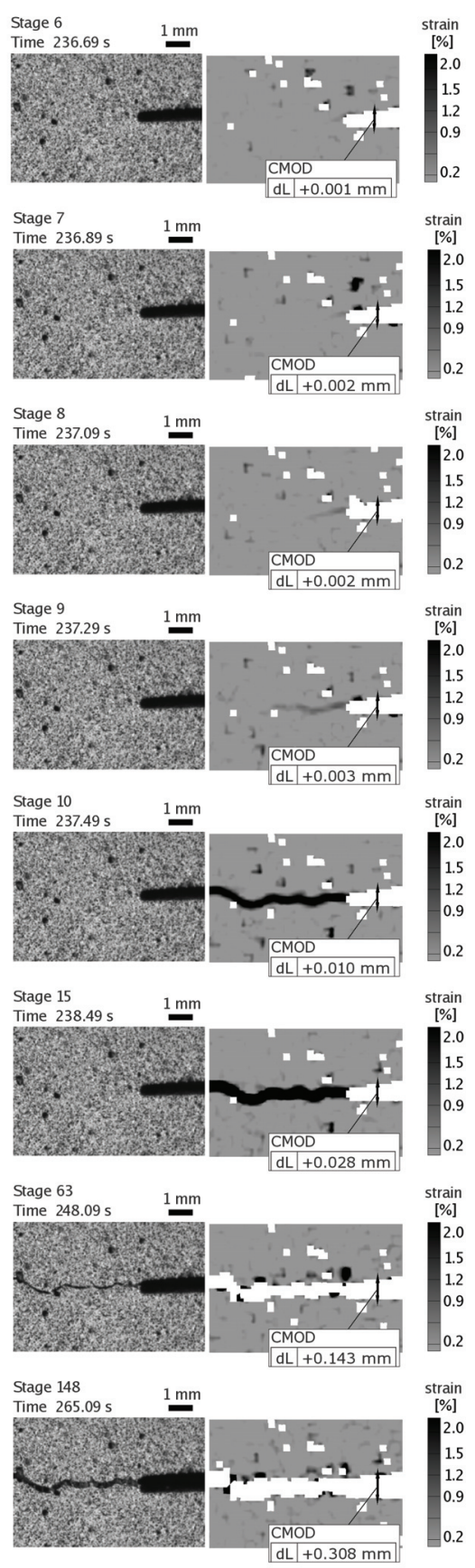

Figure 21: Detailed analysis near the notch tip, showing cracking initiation and propagation. 


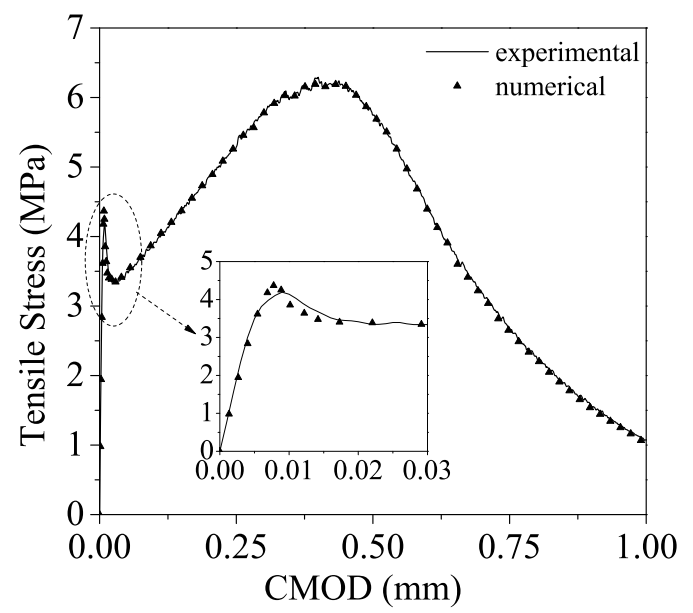

Figure 22: Numerical simulation of the entire tensile stress-CMOD response obtained for the 2\% PVA fiber reinforced cementitious composite.

traction-separation law adopted in the numerical model is derived utilizing the experimental tensile stress-crack opening curve, the described effect may justify the small difference observed at the initial part of the response, during the crack initiation and propagation stages.

To compare the crack profiles obtained with the image-based analysis and the numerical simulation, two distinct loading stages were selected. The crack profiles measured with the image-based analysis system at stages 9 and 15 (see Figure 19) are compared with the crack profiles obtained in the numerical model at the load increments where the same CMOD was measured (Figure 23). In the image-based analysis, the crack opening displacement $(\delta)$ was measured in 30 equally spaced points along the crack path, using virtual clip gages with a length of $5 \mathrm{~mm}$. The crack opening displacements measured are compared with the crack profiles obtained in the numerical model for one half of the ligament, with coordinate $x_{1}$ starting at the center of the ligament 


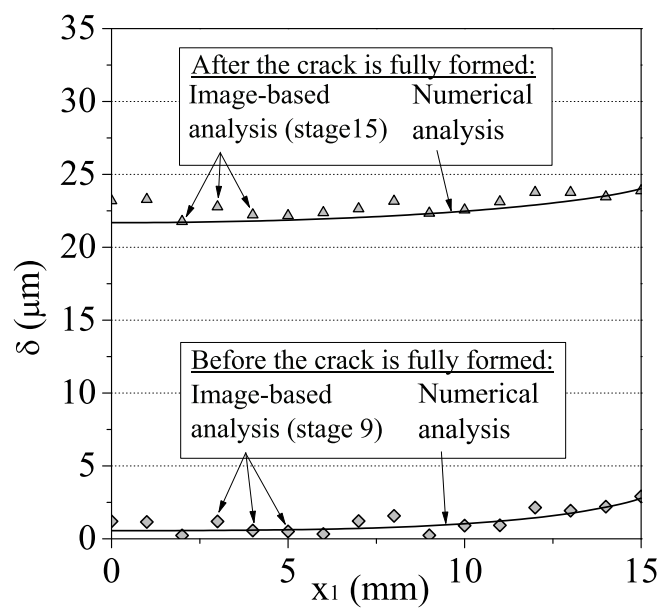

Figure 23: Crack profiles obtained in two stages of the cracking process, before and after the crack is fully formed.

and ending at the tip of the notch $\left(x_{1}=15 \mathrm{~mm}\right.$, see Figure 6$)$.

\section{Tensile stress-crack opening behavior in dogbone-shaped speci- mens}

The tensile stress-strain behavior typically observed in SHCC specimens under direct tension is characterized as a tensile pseudo-strain hardening behavior. The overall tensile hardening experienced by SHCC specimens in tension occurs while the deformation in the loading direction significantly increases due to the formation of multiple parallel cracks perpendicular to the loading direction. This pseudo-strain hardening behavior in tension and the formation of multiple parallel cracks are possible because individual cracks in the SHCC material are deliberately designed to have a higher ultimate fiber bridging stress compared to the first cracking strenth. Furthermore, the fracture energy involved in the formation of an individual crack must meet an 
additional criterion for multiple cracking criterion to occur [6]. SHCC materials are micro-mechanically designed to withstand increasing tensile stresses after the formation of cracks. Although the cement-based matrix is brittle, the fiber bridging stresses at a crack exceed the cracking stress of the cementbased matrix, therefore allowing the formation of additional parallel cracks before ultimate failure. As a result of this multiple cracking in tension, SHCC materials exhibit high toughness and ductile behavior in tension.

The importance of the fiber bridging mechanisms to the pseudo-strain hardening behavior is the motivation in the investigation of the tensile behavior of SHCC at the level of a single crack. In a previous section, the procedure utilized to characterize the tensile stress-crack opening behavior of various fiber reinforced cementitious composites was described. To evaluate how these results compare with experimentally obtained data of the tensile stress-crack opening behavior in dogbone specimens with multiple crack formation, in Figure 24 the tensile stress-strain behavior obtained for the composite containing $2.0 \%$ of PVA fibers is shown (cite Larus work). Dogbone specimens with fixed rotation boundary conditions were subjected to a constant tensile displacement rate of $1.0 \mathrm{~mm} / \mathrm{min}$. The specimens reached a tensile strength of $4.2 \mathrm{MPa}$ at a tensile strain of $4.5 \%$. In a closer view of the results obtained up to a tensile strain of $2.5 \%$, tensile hardening is observed while the tensile deformation significantly increases. The formation of several parallel cracks was verified during testing until tensile failure of the specimens occurred with the localization of the deformations at one crack, after cracking saturation.

The image-based analysis described in previous section was utilized to in- 


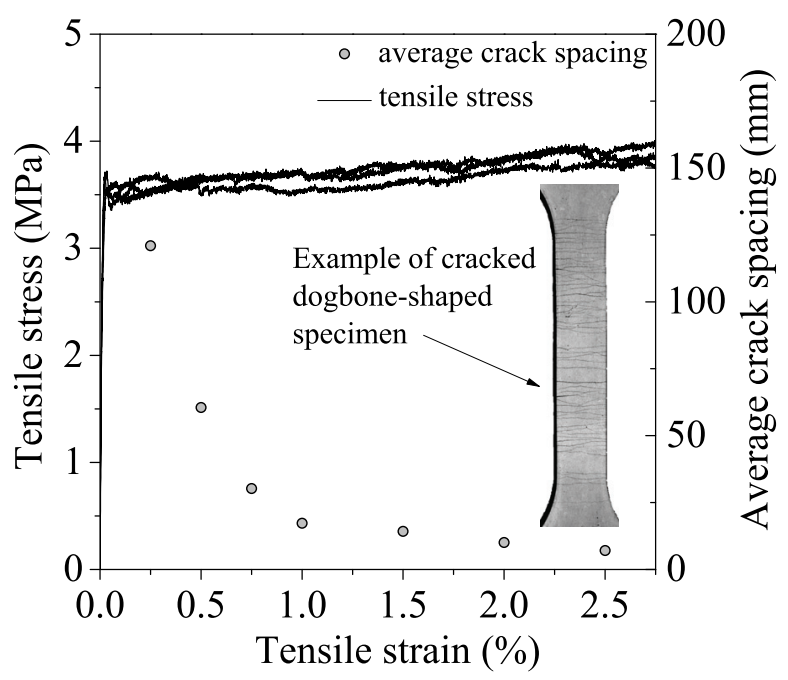

Figure 24: Tensile stress-strain curves and average crack spacing obtained from three dogbone-shaped specimens of $2 \%$ PVA fiber reinforced cementitious composite.

terpolate the displacements at the surface of the specimens during the entire loading sequence. Using the results of the image-based deformation analysis, it was possible to trace the evolution of the tensile stress-crack opening displacement at each crack during testing. The nominal tensile stress was obtained by dividing the tensile load by the net area of the specimen cross section, $25 \times 50 \mathrm{~mm}^{2}$. The tensile stress-crack opening behavior was characterized at 30 cracks. In Figure 25 the setup used to measure the deformations at the surface of the dogbone-shaped specimen is explained. The strain overlay, resulting from the image-based deformation analysis, reveals the formation of cracks at the early stage of the tensile loading, as shown at a tensile strain of $0.6 \%$. At incr $\bigcirc$ ing tensile strain the cracks become clearly visible, as shown at a tensile strain of $3.2 \%$. The crack opening at three representative cracks was traced during the entire loading sequence us- 


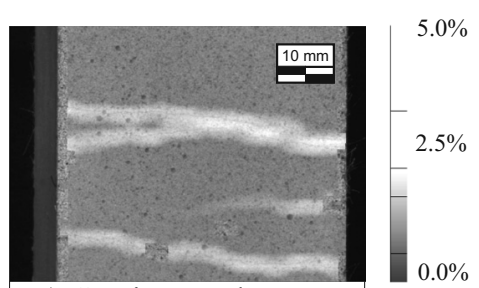

a) Strain overlay

(tensile strain $=0.6 \%$ )

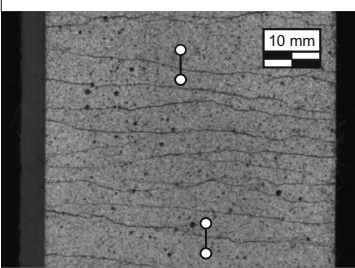

b) Virtual clip gages

(tensile strain $=3.2 \%$ )

Figure 25: Schematic of the cracked dogbone specimen and results obtained with the image-based deformation analysis: a) cracked surface and strain overlay at $0.6 \%$ of tensile strain and b) cracked surface at $3.2 \%$ of tensile strain and positioning of two virtual clip gages used to monitor the crack opening displacements.

ing the virtual clip gages, as exemplified. In Figure 26 the tensile stress-crack opening obtained for these three representative cracks is shown.

Due to the typical scatter of sectional properties in cement-based composites, the first cracking strength and the density of fiber distribution are different at each location of the specimen, therefore a range of tensile stresscrack opening behaviors are expected at the observed crack locations. Within this range, a general trend can be observed as initial crack widening at almost constant tensile stress, followed by tensile hardening identical to the observed in the SCTT. As a result of the interaction between the cracks during the formation and propagation phase in the dogbone-shaped specimen, a 


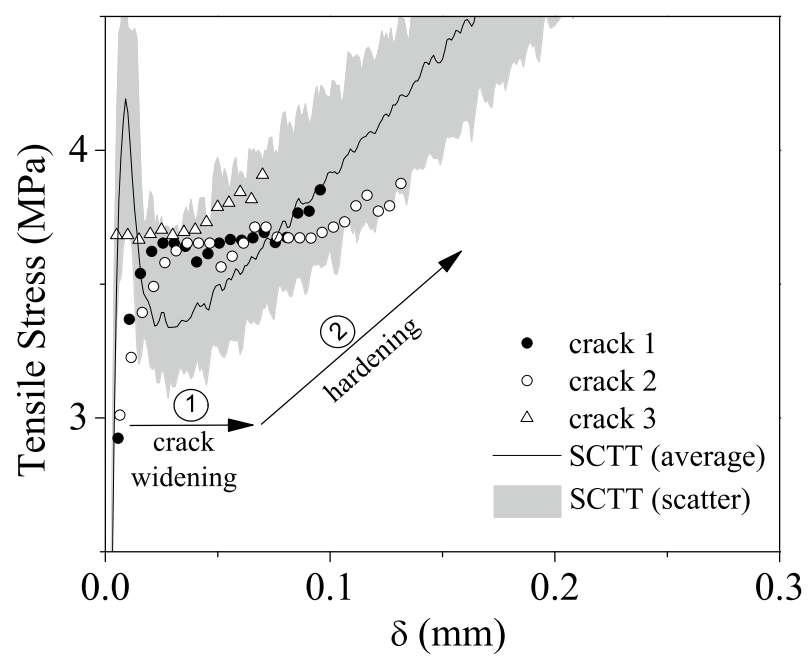

Figure 26: Tensile stress-crack opening $(\delta)$ curves obtained at three representative cracks and comparison with the SCTT results.

full interpretation of the mechanisms governing the overall behavior observed is complex and out of the scope of the present investigation. In general the results suggest that once the cracks have propagated through the specimen cross-section and the deformations have reached a steady state, the tensile stress-crack opening behaviors observed in the dogbone-shaped specimen are found within the range predicted by the SCTT. The tensile strength observed in the SCTT is not reached because the crack that determines the rupture of the dogbone-shaped specimen is the weakest in terms of bridging tensile strength. Therefore, for simulation or design purposes, a probabilistic description of the tensile stress-crack opening behavior characterized with the SCTT is necessary. 


\section{Discussion}

The results obtained with the seven different composites showed, in general, a good agreement between different tests for each composite. As shown in Figure 4, the results are consistent and reasonable, revealing the intrinsic mechanics of each composite system. The influence of the geometrical and mechanical parameters of each fiber reinforcing system can be identified and studied. The activation of fibers with different diameters has been shown to occur at different stages of the cracking process. The PAN fibers, with a smaller diameter, were activated even before the first cracking strength was reached, and contributed effectively to the increase of the cracking peak stress. Their premature activation was followed by an also premature exhaustion of their contribution to the post-cracking tensile behavior. The contribution of PVA and PP fibers to the increase of the first cracking strength was negligible. Instead their full mobilization occurs after cracking, with significant tensile hardening ramps developing after cracking in both cases. The main difference between the SCTT results observed for PVA and PP fiber reinforced composites was located in the region of the tensile stress-crack opening curves where the peak bridging stress is reached. While for the PVA fiber reinforced composites the experimental curves exhibited a sharp transition between the tensile hardening and the tensile softening stages, with the PP reinforced composites this transition occurs gradually and smoothly. The well known superior interfacial bonding of the PVA fibers with the matrix may justify these results, as opposed to the poorer bonding of the PP fibers due to their hydrophobic nature $[32,33]$. Therefore, the gradual increase of the tensile stress in the fibers, during the composite tensile hardening 
stage after cracking, causes the premature debonding of a gradually increasing number of PP fibers, resulting in the also gradual decrease of the tensile hardening stiffness for increasing CMOD and the observed smooth transition to softening. The superior bonding of the PVA fibers with the matrix results in a constant tensile hardening stiffness after cracking, with most of the fibers being fully mobilized. Once the applied tensile stress in the composite approaches the peak bridging stress, the great majority of active fibers start rupturing. Therefore the tensile softening occurs more rapidly with the PVA fiber reinforced composite than with the PP fiber one, exhibiting the tensile stress-crack opening curve a sharp transition from the tensile hardening to the tensile softening stages. In addition, the composites reinforced with PP fibers maintain higher residual tensile strengths, as a result of the reduced interfacial bonding and the preservation of a higher number of active fibers for greater CMOD.

The obtained results suggest that a group of generic stages of a typical tensile stress-crack opening behavior can be distinguished. At the onset of tensile testing, the mechanical response starts with what is usually assumed as the predominantly elastic behavior, with a steep increase in the applied load while tensile deformation increases. This first stage ends when the nominal matrix cracking strength is achieved, with the rapid transfer of the tensile stresses from the cracked matrix to the fibers and the subsequent rapid tensile load decay. Preliminary stages of micro-cracking and microdefect propagation may affect the shape of this transition stage, governed by fracture mechanisms and dependent on the shape and size of pores and micro-defects. The micro-mechanisms taking place at this stage were system- 
atically discussed in the previous section, supported by the numerical model and the image-based monitoring results. Fibers may also play a role at this stage as crack inducers, but the extension of the experimental data available is not detailed enough to allow a thorough analysis of this mechanism. Packing density of the solid skeleton is also influenced by the presence of the fibers and their geometry, which in turn affect the matrix fracture properties.

After the rapid load decay caused by the transfer of the tensile stresses from the matrix to the fibers, a new hardening stage supported by the full mobilization of the fiber-matrix bonding mechanisms is initiated. While the fibers stretch, hardening occurs until the peak bridging stress is reached. In this third stage the stiffening effect of the fiber reinforcement is exhausted either due to fiber debonding and slip-softening pull out mechanisms or fiber rupture. The result is respectively a sharp or a smooth transition between the tensile hardening and softening stages.

The fourth stage consists of the post-peak softening stage observed in all curves. It coincides with the gradual neutralization of the remaining links between opposite crack faces. This stage may be divided into two different branches with different inclinations, one steeper and other mostly horizontal, influenced by the geometry and the mechanical properties of the aggregates and the fibers.

The sequence of stages previously described consists of an interpretation of complex mechanisms taking place at the level of a single crack in the bulk composite, which summarize and condense in a rational way the tensile behaviors observed, useful from a design perspective. In Figure 27, this systematic approach of the tensile stress-crack opening behavior is summarized 


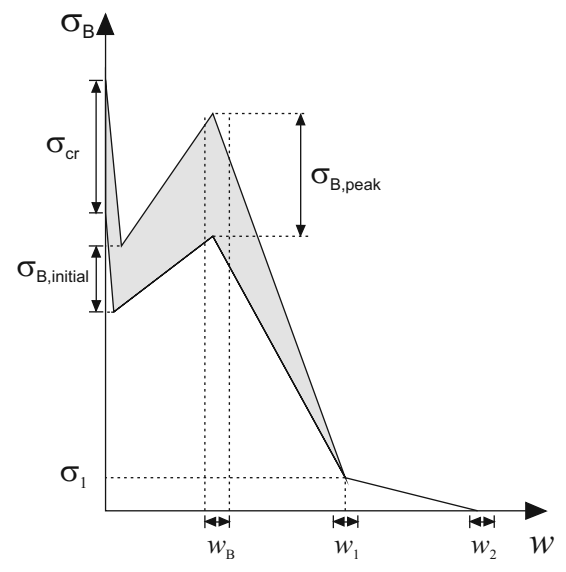

Figure 27: Tensile stress-crack opening design law for SHCC [34].

649

in the shape of a constitutive design law [34].

The identification of the parameters defining the shape of the bridging stress, $\sigma_{B}$, versus the crack opening, $w$, relationship may be carried out experimentally using the SCTT. For that purpose the test setup conditions suggested above can be adopted. The first cracking strength, $\sigma_{c r}$, the initial bridging stress, $\sigma_{B \text {,initial }}$, the peak bridging stress, $\sigma_{B, \text { peak }}$, and the corresponding crack opening at peak bridging stress, $w_{B}$, represent the most significant parameters to be identified. Subsequently the residual bridging stress, $\sigma_{1}$, the corresponding crack opening, $w_{1}$, and finally the ultimate cohesive crack opening, $w_{2}$, represent also important design parameters. All this data, and the scatter associated to each of these parameters, may be used to support the structural design and to define reliability factors for each mechanical parameter. Alternatively, the material requirements may be imposed by the structural concept. These requirements may assume the shape of a predefined bridging stress-crack opening curve, which will guide 
the material design with a fiber reinforced cementitious composite based solution. Material and structural design may be integrated with this approach. The sequence of distinctive stages above mentioned is clearly identifiable in all tested composites. The adopted fiber reinforcements show different mechanical performances in tension, however these stages remain clearly distinctive and keep the same formal details. This suggests that a rational design approach can be based on the assumption that the tensile stress-crack opening behavior of fiber reinforced cementitious composites follows a standard sequence of stages assuming the shape of a generic tensile stress-crack opening design curve (see Figure 27).

\section{Conclusions}

The objective of characterizing the tensile behavior of SHCC at the level of a single crack described in this study was approached by performing the proposed single crack tension test (SCTT). The formation of a single, localized crack was consistently confirmed using tension softening and pseudostrain hardening materials. With the purpose of understanding the nature and topology of the cracks generated when using the proposed SCTT setup, the crack formation and propagation stages during testing were documented using an image-based deformation analysis system. This procedure allowed the visualization of the displacements at the surface of the specimen with reasonable accuracy. The initiation and propagation of a single crack during the pre- and post-cracking stages were observed and the measured crack profiles during testing showed good correlation with the crack profiles ob- 
tained at the same CMOD using the numerical simulation. While utilizing the tensile stress-crack opening responses to derive the cohesive law, the numerical model results were also in good agreement with the experimental tensile stress-CMOD responses, supporting the assumption of a single crack forming during the loading sequence in the SCTT. In particular, the geometry and reduced thickness of the adopted notches were demonstrated to have an important effect in the formation of a single crack during loading process.

The activation of fibers with different diameters occurred at different stages of the cracking process of SCTT. The fibers of smaller diameter showed significant activity even before the first cracking strength was reached, contributing effectively to the increase of the first cracking strength. The fibers with larger diameter have demonstrated an effect only after crack formation, contributing to the development of considerable post-cracking tensile hardening. The main difference between the tensile stress-crack opening behaviors observed with PVA and PP fibers was located at the region where the peak bridging stress is reached. While the PVA reinforced composites exhibited a sharp transition between the tensile hardening and softening stages, in the PP reinforced composites this transition was smooth and the peak bridging stress reached was lower. The SCTT showed high sensitivity to important composite properties, such as the different interfacial bonding characteristics, fiber properties and pull-out conditions established between the fibers and the matrix, which makes SCTT very attractive to support the design process of these materials.

The assessment of the tensile stress-crack opening behavior is important to the material constitutive modeling and the design of structures based on 
the finite element method. The response obtained can be summarized into a group of relevant fracture parameters, depending on the precision required in the design process. In terms of the material properties of SHCC, the design procedure may be based on a set of requirements established with respect to the main parameters characterizing the tensile stress-crack opening behavior, including the first cracking strength, the fiber bridging stiffness, the ultimate bridging strength and the crack opening at reaching the fiber bridging strength. The SCTT setup allows the explicit characterization of the stress-crack opening behavior and may therefore guide the process of designing and optimizing SHCC materials, as well as aid with the integration of material selection in the structural design process.

\section{Acknowledgments}

The authors thank the Portuguese National Science Foundation for the financial support, through grant SFRH / BD / 36515 / 2007, funded by POPH-QREN, the Social European Fund and the MCTES, and DTU-Byg for their support of the work as part of this project.

[1] V. C. Li, Large volume, high-performance applications of fibers in civil engineering, Journal of Applied Polymer Science 83 (2002) 660-686.

[2] A. M. Brandt, Fibre reinforced cement-based (frc) composites after over 40 years of development in building and civil engineering, Compos Struct 86 (2008) 3-9. 
[3] G. Fischer, V. C. Li, Effect of fiber reinforcement on the response of structural members, Eng Frac Mech 74 (2007) 258-272.

[4] V. C. Li, On engineered cementitious composites (ecc), J Adv Conc Tech 1 (2003) 215-230.

[5] A. E. Naaman, H. W. Reinhardt, Proposed classification of hpfrc composites based on their tensile response, Mater Struct 39 (2006) 547-555.

[6] T. Kanda, V. C. Li, Practical design criteria for saturated pseudo strain hardening behavior in ecc, J Adv Conc Tech 4 (2006) 59-72.

[7] K. Rokugo, T. Kanda, H. Yokota, N. Sakata, Applications and recommendations of high performance fiber reinforced cement composites with multiple fine cracking (hpfrcc) in japan, Mater Struct 42 (2009) 1197-1208.

[8] S. Quian, V. C. Li, Simplified inverse method for determining the tensile properties of strain hardening cementitious composites (shcc), Journal of Advanced Concrete Technology 6 (2008) 353-363.

[9] B. Cotterell, Y.-W. Mai, Fracture mechanics of cementitious materials, Blackie, London, 1996.

[10] B. Karihaloo, Fracture mechanics and structural concrete, Longman Scientific and Technical, Harlow, 1995.

[11] S. Shah, S. Swartz, C. Ouyang, Fracture mechanics of concrete - Applications of fracture mechanics to concrete, rock, and other quasi-brittle materials, Wiley, New York,N.Y., 1995. 
[12] I. Lofgren, H. Stang, J. F. Olesen, The wst method, a fracture mechanics test method for frc, Mater Struct 41 (2008) 197-211.

[13] Rilem tc 162-tdf: Bending test, Materials and Structures 35 (2002) 579-582. 10.1007/BF02483127.

[14] V. C. Li, H. Stang, H. Krenchel, Micromechanics of crack bridging in fibre-reinforced concrete, Mater Struct 26 (1993) 486-494.

[15] Rilem tc 162-tdf: Uni-axial tension test for steel fibre reinforced concrete, Materials and Structures 34 (2001) 3-6. 10.1007/BF02482193.

[16] S. Shah, A. Brandt, C. Ouyang, R. Baggott, J. Eibl, M. Glinicki, H. Krenchel, A. Lambrechts, V. C. Li, B. Mobasher, L. Taerwe, Toughness characterization and toughening mechanisms., in: R. H. W. Naaman A. E. (Ed.), High performance fiber reinforced cement composites 2, volume 31 of RILEM Proceedings, E \& FN Spon, 1996, pp. 194-224.

[17] G. Fischer, H. Stang, L. Dick-Nielsen, Initiation and development of cracking in ecc materials: Experimental observations and modeling, in: G. P. Carpinteri GFA. (Ed.), High Performance Concrete, Brick- Masonry and Environmental Aspects., volume 3, FraMCos, Taylor \& Francis, 2007, pp. 1517-1522.

[18] E. H. Yang, S. Wang, Y. Yang, V. C. Li, Fiber-bridging constitutive law of engineered cementitious composites, Journal of Advanced Concrete Technology 6 (2008) 181-193. 
[19] P. Kabele, Multiscale framework for modeling of fracture in high performance fiber reinforced cementitious composites, Eng Frac Mech 74 (2007) 194-209.

[20] P. Kabele, Finite element fracture analysis of reinforced shcc members, in: G. van Zijl, W. Boshoff (Eds.), Advances in Cement-Based Materials, volume International Conference on Advanced Concrete Materials, Stellenbosch, South Africa, pp. 237-244.

[21] A. E. Naaman, G. Fischer, N. Krustulovic-Opara, Measurement of tensile properties of fiber reinforced concrete: draft submitted to aci committee 544, in: R. H. W., N. A. E. (Eds.), Rilem International Workshop on High Performance Fiber Reinforced Cement Composites, number Pro. 53 in RILEM Proceedings, RILEM, RILEM S.A.R.L, 2007, pp. 3-12.

[22] T. C. Chu, W. F. Ranson, M. A. Sutton, Applications of digital-imagecorrelation techniques to experimental mechanics, Exp Mech 25 (1985) $232-244$.

[23] T. Berfield, J. Patel, R. Shimmin, P. Braun, J. Lambros, N. Sottos, Micro-and nanoscale deformation measurement of surface and internal planes via digital image correlation, Exp Mech 47 (2007) 51-62.

[24] V. C. Li, S. Wang, C. Wu, Tensile strain-hardening behavior or polyvinyl alcohol engineered cementitious composite (pva-ecc), ACI Mater J 98 (2001) 483-492. 
[25] C. euro-international du beton, CEB-FIP model code 1990: design code, number 213-214 in Design Code, T. Telford, 1993.

[26] Z. P. Bazant, P. A. Pfeiffer, Determination of fracture energy from size effect and brittleness number., ACI Mater J ACI materials journal 84 (1987) 463-480.

[27] Z. Bazant, M. Kazemi, Determination of fracture energy, process zone length and brittleness number from size effect, with application to rock and concrete, Int J Fract 44 (1990) 111-131.

[28] D. A. Lange, H. M. Jennings, S. P. Shah, Relationship between fracture surface roughness and fracture behavior of cement paste and mortar, J Am Ceram Soc 76 (1993) 589-597.

[29] H. Stang, T. Aarre, Evaluation of crack width in frc with conventional reinforcement, Cem Conc Comp 14 (1992) 143-154.

[30] J. Bolander, J., H. Hirosaka, Simulation of fracture in cement-based composites, Cem Conc Comp 17 (1995) 135-145.

[31] K. Otsuka, H. Date, Fracture process zone in concrete tension specimen, Eng Frac Mech 65 (2000) 111-131.

[32] V. C. Li, S. Wang, A. Ogawa, T. Saito, C. Wu, Interface tailoring for strain-hardening polyvinyl alcohol-engineered cementitious composite (pva-ecc), ACI Mat J 99 (2002) 463-472.

[33] Q. F. Wei, R. R. Mather, A. F. Fotheringham, R. D. Yang, Esem study 
${ }_{821}$ of wetting of untreated and plasma treated polypropylene fibers, J Ind $822 \quad$ Text $32(2002)$ 59-66.

[34] J. Yang, G. Fischer, Investigation of the fiber bridging stress-crack opening relationship of fiber reinforced cementitious composites, in: International Workshop on High Performance Fiber Reinforced Cementitious Composites in Structural Applications, volume RILEM Proceedings PRO 49, pp. 93-106. 